\title{
Synthesis of molybdenum-doped rhenium disulfide alloy using aerosol-assisted chemical vapour deposition
}

DOI:

10.1016/j.mssp.2021.105718

\section{Document Version}

Accepted author manuscript

Link to publication record in Manchester Research Explorer

\section{Citation for published version (APA):}

Al-dulaimi, N., Al-shakban, M., Lewis, E. A., Mcnaughter, P. D., Alam, F., Haigh, S. J., \& Lewis, D. J. (2021). Synthesis of molybdenum-doped rhenium disulfide alloy using aerosol-assisted chemical vapour deposition. Materials science in semiconductor processing, 127, 105718. https://doi.org/10.1016/j.mssp.2021.105718

\section{Published in:}

Materials science in semiconductor processing

\section{Citing this paper}

Please note that where the full-text provided on Manchester Research Explorer is the Author Accepted Manuscript or Proof version this may differ from the final Published version. If citing, it is advised that you check and use the publisher's definitive version.

\section{General rights}

Copyright and moral rights for the publications made accessible in the Research Explorer are retained by the authors and/or other copyright owners and it is a condition of accessing publications that users recognise and abide by the legal requirements associated with these rights.

\section{Takedown policy}

If you believe that this document breaches copyright please refer to the University of Manchester's Takedown Procedures [http://man.ac.uk/04Y6Bo] or contact uml.scholarlycommunications@manchester.ac.uk providing relevant details, so we can investigate your claim.

\section{OPEN ACCESS}




\section{Synthesis of Molybdenum-Doped Rhenium Disulfide Alloy using Aerosol-}

\section{Assisted Chemical Vapour Deposition}

Naktal Al-Dulaimi, ${ }^{* 1,2}$ Mundher Al-Shakban, ${ }^{3}$ Edward A. Lewis, ${ }^{4}$ Paul D. McNaughter, ${ }^{2}$ Firoz Alam, ${ }^{2}$ Sarah J. Haigh, ${ }^{4}$ David J. Lewis ${ }^{4}$

${ }^{1}$ Department of Applied Chemistry, Medical and Applied Science College, Charmo University, 46023 Chamchamal-Sulaimani, Kurdistan Region, Iraq.

${ }^{2}$ Department of Chemistry, The University of Manchester, Oxford Road M13 9PL, U.K

${ }^{3}$ Department of Physics, College of Science, University of Misan, Maysan, Iraq

${ }^{4}$ Department of Materials, The University of Manchester, Oxford Road, M13 9PL, U. K.

Dr. Naktal Al-Dulaimi, Charmo University, 46023 Chamchamal-Sulaimani, Kurdistan Region, Iraq.

Email: naktal.abdulhafedh@charmouniversity.org Tel: +9647725425217 


\begin{abstract}
Polycrystalline thin films of molybdenum-doped rhenium disulphide (Mo-doped $\mathrm{ReS}_{2}$ ) alloys were synthesised by aerosol-assisted chemical vapour deposition (AACVD) using precursor solutions containing (1) $\left[\mathrm{Re}\left(\mathrm{S}_{2} \mathrm{CC}_{6} \mathrm{H}_{5}\right)\left(\mathrm{S}_{3} \mathrm{CC}_{6} \mathrm{H}_{5}\right)_{2}\right]$, and (2) $\left[\mathrm{Mo}\left(\mathrm{S}_{2} \mathrm{CNEt}_{2}\right)_{4}\right]$. Synthesised thin films were characterised using powder X-Ray diffraction (p-XRD), Raman spectroscopy, scanning electron microscope (SEM), transmission electron microscope (TEM), inductively coupled plasma-optical emission spectrometry (ICP-OES) and energy dispersive X-Ray $(E D X)$. The p-XRD shows that interlayer spacing increases with increasing Mo content in the $\mathrm{ReS}_{2}$ matrix, and (001) plane becomes broad and weak as the molybdenum increases in the doped films. The destruction of the vibrational modes of $\operatorname{ReS}_{2}$ on increasing the Mo content and a clear shift in the $\mathrm{E}_{\mathrm{g}}$ vibrational and $\mathrm{A}_{\mathrm{g}-\text { like }}$ modes were also observed by Raman analysis. The presence of Mo in the $\mathrm{ReS}_{2}$ matrix was detected by ICP-OES. It was observed that the Mo content in the final material was 7.61 at $\%$ compared to the initial feed of 15 at $\%$. The SEM images of the doped alloy films revealed nano crystal morphology, and the morphology changed when there was an increase in the Mo portion into the $\mathrm{ReS}_{2}$ crystal structure.
\end{abstract}

\title{
Keywords: AACVD; Rhenium disulfide; Doping; Mo-doped ReS2; Doped transition metal dichalcogenides; TMDCs.
}




\section{Introduction}

Transition-metal dichalcogenides (TMDCs) are semiconductors with the general formula $\mathrm{MX}_{2}$, where $\mathrm{M}$ is a transition metal, such as (rhenium, molybdenum, cadmium and iron), and $\mathrm{X}$ is a chalcogen, such as $\mathrm{S}, \mathrm{Se}$, Te, have received a considerable attention because of their potential applications in electronic, optoelectronic and energy storage. Chemical vapour deposition (CVD) and physical vapour transport (PVT) are the most commonly used methods to produce TMDCs [1]. Both the lateral size and the number of layers can be controlled using these methods, and this is important when tuning the optical and electronic properties of layered TMDCs [2].

Two-dimensional (2D) transition metal dichalcogenides (TMDs) are a new class of electronic materials contribute great chances for advanced technologies. 2D TMDs materials have unique physicochemical properties and show broad prospects in energy storage [3, 4], optoelectronics, spintronics, high-end electronics [5], and a direct bandgap [6]. Their electronic properties can be control by doping [7]. Therefor, the doping is important to inhance and control their properties for different application.

Rhenium disulfide $\left(\operatorname{ReS}_{2}\right)$, a new member in the TMDCs family, has received considerable attention due to its direct band gap nature in the bulk and monolayer form [8]. Its direct bandgap value for bulk to monolayer is $1.5 \mathrm{eV}[8,9]$. $\operatorname{ReS}_{2}$ has electronic band structures, which are different from other TMDCs. Most of the research studies on metal sulfide revealed that they are isotopological; however, unlike most other TMDCs $\mathrm{ReS}_{2}$ has a direct band gap in both bulk and monolayer form, and this is due to its band structures that show metallic character, in rhenium atoms the band that crosses the Fermi level comes from the $5 d$-orbitals. In the monolayer form this band is not separated [10]. Unlike $\operatorname{ReS}_{2}$, molybdenum disulfide $\left(\mathrm{MoS}_{2}\right)$ materials have an indirect-band-gap in the bulk form and a direct-band-gap in the monolayer form [11]. Doped TMDCs have promising technological potential, particularly in catalysis and nanoelectronics [10]. Transition metal (TM)-doped TMDCs can be used as an alternative process to expand the current technology instead of changing to a new one. However, doping TMDCs could be unsuitable in some applications. Therefore, the synthesising of a few monolayer TMDCs and controlling their composition is vital for their technological use [12]. The synthesis of Mo-doped $\mathrm{ReS}_{2}$ alloys is still a challenge, and it is difficult to detect Mo in $\operatorname{ReS}_{2}$ lattice [13]. However, both $\operatorname{Re}(\mathrm{IV})$ and Mo(IV) have similar ionic radii of 0.63 and 0.65 $\AA$, respectively [14]; therefore, doping should be possible. A pure thin film of metal 
chalcogenide, as well as perovskite materials, can be produced using aerosol-assisted chemical vapour deposition (AACVD) [15], such as $\operatorname{ReS}_{2}$ [16], pyrite $\left(\mathrm{FeS}_{2}\right)$ [17, 18], $\mathrm{WS}_{2}$ [19], cadmium sulfide (CdS) [20], tin(II) sulfide (SnS) [21, 22] and $\mathrm{MAPBr}_{3}$ [23]. TM-doped $\mathrm{MoS}_{2}$ can also be produced using AACVD [24-26].

Recently, molybdenum-doped $\mathrm{ReS}_{2}$ has received attention, few layered $\mathrm{ReS}_{2} / \mathrm{MoS}_{2}$ films with different Re/Mo atomic ratio were synthesised. The compositions the heterojunctioned films were controlled by controlling the ratio of Re to Mo atom. The study show that the adhesion force can be control [27]. The electrical properties of monolayer of Mo-doped $\mathrm{ReS}_{2}$ were investigated and display gate-tunable current rectification behavior [28].

The Mo-doped $\mathrm{ReS}_{2}$ with few nanosheets thickness and control Mo-dopant contents have been synthesised. The effect of Mo on hydrogen evolution reaction activities of the doped materials were studied, and revealed an optimal hydrogen evolution reaction activities performance [29]. Molybdenum-doped $\operatorname{ReS}_{2}$ was synthesised using chemical vapor deposition, doped alloy has been shown to possess a bowing effect with phase transition from octahedral (1T) to hexagonal $(2 \mathrm{H})$ [30]. In this paper, Mo-ReS 2 alloyed film was produced using (1) $\left[\mathrm{Re}\left(\mathrm{S}_{2} \mathrm{CC}_{6} \mathrm{H}_{5}\right)\left(\mathrm{S}_{3} \mathrm{CC}_{6} \mathrm{H}_{5}\right)_{2}\right]$ and (2) $\left[\mathrm{Mo}\left(\mathrm{S}_{2} \mathrm{CNEt}_{2}\right)_{4}\right]$ precursors using AACVD. These precursors have been synthesised according to previously reported literature methods [31, 32]. The Molybdenum is a promising hole donor because Mo atom has one valence electron less than rhenium, therefore, it is the best candidate for p-type doping of $\operatorname{ReS}_{2}$ [33].

\section{Experimental}

\subsection{Deposition of thin films using aerosol-assisted chemical vapor deposition (AACVD)}

Thin films were produced using aerosol-assisted chemical vapour deposition technique (AACVD). The apparatus was used to produce Mo-doped $\mathrm{ReS}_{2}$ alloyed is shown in Fig. S1. In all portions a $0.1 \mathrm{mmol}$ of total precursors (1) $\left[\mathrm{Re}\left(\mathrm{S}_{2} \mathrm{CC}_{6} \mathrm{H}_{5}\right)\left(\mathrm{S}_{3} \mathrm{CC}_{6} \mathrm{H}_{5}\right)_{2}\right]$ and (2) $\left[\mathrm{Mo}\left(\mathrm{S}_{2} \mathrm{CNEt}_{2}\right)_{4}\right]$ have been used. The precursors were dissolved in tetrahydrofuran $(20 \mathrm{~mL})$ loaded in the same vessel. Glass substrates were loaded into the tube furnace, which heated to the desired temperature $\left(550{ }^{\circ} \mathrm{C}\right)$ for deposition thin films. The aerosol of the solution is generated using piezoelectric humidifier which was delivered as a precursors mist to a quartz tube containing the substrates $(3 \mathrm{~cm} \mathrm{x} 1 \mathrm{~cm})$ that placed in the tube furnace. Argon was used as carrier gas with flow rate $180 \mathrm{sccm}$. 


\subsection{Synthesis of $\left(\left[\operatorname{Re}\left(\mathrm{S}_{2} \mathrm{CC}_{6} \mathrm{H}_{5}\right)\left(\mathrm{S}_{3} \mathrm{CC}_{6} \mathrm{H}_{5}\right)_{2}\right]\right)(1)$}

The compound $\left[\operatorname{Re}\left(\mathrm{S}_{2} \mathrm{CC}_{6} \mathrm{H}_{5}\right)\left(\mathrm{S}_{3} \mathrm{CC}_{6} \mathrm{H}_{5}\right)_{2}\right]$ was synthesised as described in previous literature[16, 31, 34]. Briefly, the precursor was synthesised by reacting 1:2 mol ratio of $\left[\left(\mathrm{Et}_{4} \mathrm{~N}\right) \mathrm{ReS}_{4}\right]$, which was synthesised as previously reported[34], and $\left[\left(\mathrm{S}_{2} \mathrm{CC}_{6} \mathrm{H}_{5}\right)_{2}\right]$ in $50 \mathrm{ml}$ of dry acetonitrile under an inert atmosphere of dry nitrogen using the standard Schlenk line for $48 \mathrm{~h}$. The green precipitate was then filtered, washed with hexane and then recrystallized with hexane and hot $\mathrm{CH}_{2} \mathrm{Cl}_{2}(1: 1)$, yield was (60.4\%). Anal. Calc. (\%) for $\left[\left(\mathrm{C}_{21} \mathrm{H}_{15} \mathrm{ReS}_{8}\right)\right] \mathrm{C}$, 35.56; H, 2.13; S, 36.06; Found (\%) C, 35.56; H, 2.52; S, 35.79. 1H NMR (400 MHz, dichloromethane -d2) $\delta /$ ppm $1.18(\mathrm{~s}, 1 \mathrm{H}) 1.26(\mathrm{tt}, \mathrm{J}=7.31,1.77 \mathrm{~Hz}, 9 \mathrm{H}) 3.28(\mathrm{q}, \mathrm{J}=7.31$ Hz, $6 \mathrm{H})$ 7.24-7.41 (m, 9 H) 7.41-7.53 (m, 7 H) 7.56-7.69 (m, 3 H) 7.88-8.07 (m, 7 H). 13C NMR 13C NMR (101 MHz, dichloromethane-d2) $\delta$ ppm 124.59 (s, 1 C) 127.60 (s, 1 C) 128.34 (s, 2 C) 131.78 (s, 2 C) 133.26 (s, 1 C) 134.79-135.02 (m, 1C).

\subsection{Synthesis of $\left(\left[\mathrm{Mo}\left(\mathrm{S}_{2} \mathrm{CNEt}_{2}\right)_{4}\right]\right)$}

The precursor was prepared as previously reported [24, 32, 35]. Briefly, a mixture of molybdenum hexacarbonyl $\operatorname{Mo}(\mathrm{CO})_{6} \quad\left(\begin{array}{lllll}10 & \mathrm{~g}, & 37.9 & \mathrm{mmol}\end{array}\right)$ and bis(diethylthiocarbamoyl)disulfide $(22.4 \mathrm{~g}, 75.6 \mathrm{mmol})$ was added to degassed acetone and the mixture was heated under reflux for $2 \mathrm{~h}$ at $58{ }^{\circ} \mathrm{C}$. The mixture was then cooled down to room temperature. As a result, crystals precipitated from the solution and were isolated by vacuum filtration, washed with pentane, and dried in vacuo to furnish the title compound (62.5\%). mp $126{ }^{\circ} \mathrm{C}-128{ }^{\circ} \mathrm{C}$. Anal. Calc (\%) C, 34.88; H, 5.86; N, 8.14; S, 37.16. Found (\%): C, 35.04; H, 6.05; N, 8.08; S, 37.33. IR ( $\left.v_{\max } / \mathrm{cm}^{-1}\right): 2970(w), 2929$ (w) 2868 (w), $1211(\mathrm{~s}), 1071,1145$, 1208. $\mathrm{MS}\left(\mathrm{ES}^{+}\right) 690.1[\mathrm{M}+\mathrm{H}]$.

\section{Results and Discussion}

Thermogravimetric analysis (TGA) was used to determine the final residue of the precursors (1) $\left[\mathrm{Re}\left(\mathrm{S}_{2} \mathrm{CC}_{6} \mathrm{H}_{5}\right)\left(\mathrm{S}_{3} \mathrm{CC}_{6} \mathrm{H}_{5}\right)_{2}\right]$ and (2) $\left[\mathrm{Mo}\left(\mathrm{S}_{2} \mathrm{CNEt}_{2}\right)_{4}\right]$ by analysing the weight loss of the precursors during the ignition process under an inert atmospheric environment. TGA analysis shows that the final residue of both (1) and (2) are $\mathrm{ReS}_{2}$ and $\mathrm{MoS}_{2}$, respectively. This result is consistent with previously reported findings $[34,36]$. The TGA of complexes (1) and (2) was used to determine the decomposition temperature for both precursors [24, 25], precursor (1) had a high decomposition temperature the last step occurred around $1000{ }^{\circ} \mathrm{C}$. Precursor (2) had four decomposition steps last step occurred at $400{ }^{\circ} \mathrm{C}$ decomposition. Therefore, the deposition 
temperature of the reactor was performed according to the rhenium precursor at $550{ }^{\circ} \mathrm{C}$. This temperature shows that $\mathrm{ReS}_{2}$ thin films were successfully produced using AA-CVD. Molybdenum-doped $\mathrm{ReS}_{2}$ alloy thin films have also been synthesised with a low concentration of Mo. The feed value of Mo in the alloy film is $2 \%, 5 \%, 10 \%$ and $15 \%$, the Inductively coupled plasma-optical emission spectrometry (ICP-OES) investigation revealed that a good percentage of Mo was incorporated into the alloy thin films and was found to be $0.84 \%, 1.29 \%$, $4.33 \%$ and $7.61 \%$, respectively (Fig. 1(i)). The disparity in feed value of Mo and incorporated value of Mo could due to the difference in crystal structure between $\operatorname{ReS}_{2}$ and $\mathrm{MoS}_{2}$, rhenium disulfide has distorted $1 T$ (octahedral) structure while $\mathrm{MoS}_{2}$ exists in $2 H$ (hexagonal) crystal structure. This difference in layer structure could make $\mathrm{ReS}_{2}$ lattice struggles to accommodate more Mo.

However, we could not detect any signature of Mo in Mo-ReS $\mathrm{S}_{2}$ alloy film by energy dispersive $\mathrm{X}$-Ray (EDX) analysis of scanning electron microscope (SEM), as Mo-doped $\mathrm{ReS}_{2}$ literature reported $[13,37]$. The Raman of Mo-doped $\operatorname{ReS}_{2}$ shows the destruction of the three vibrational modes of $\operatorname{ReS}_{2}$. By increasing the concentration of Mo to 7.61\%, all modes of $\mathrm{ReS}_{2}$ disappear. This suggests that at $7.61 \%$ dopants the long range order within the $1 T$ structure of $\operatorname{ReS}_{2}$ is lost. The powder X-Ray diffraction (p-XRD) demonstrate how the sharp (001) peak for $\mathrm{ReS}_{2}$ becomes weaker and broader by increasing the Mo content. This indicates the loss of diffracting material in the (001) plane with $d$-spacing $(6.16 \AA)$ of the distorted-1T structure of $\operatorname{ReS}_{2}$ (Fig. 1 (iii)). It can be seen from the XRD data that the $d$-spacing of the doped alloyed films increases gradually by increasing the amount of Mo in the $\mathrm{ReS}_{2}$ matrix (i.e., from (6.16 $\AA)$ in case of $\operatorname{ReS}_{2}$ to $(6.18 \AA)$ for $0.84 \% \mathrm{Mo},(6.29 \AA)$ for $1.29 \% \mathrm{Mo},(6.31 \AA)$ for $4.33 \%$ Mo and finally $(6.37 \AA)$ at $7.61 \% \mathrm{Mo})$.

These interesting findings clearly suggest that the doping of Mo shows approximate linear relationship lattice expansion in the (001) direction of the crystal lattice of $\operatorname{ReS}_{2}$ (Fig. S2). The crystal structure of molybdenum doped $\mathrm{ReS}_{2}$ shows the increase in the $d$-spacing with increasing Mo portions. Suggesting that, increasing the dopant (Mo) makes the crystal structure suffer from lattice expansion in the (001) direction. This expansion was noticed in previous works [24, 34], studies disclosed that doped-TMDs (e.g Re-doped $\mathrm{MoS}_{2}$ ) were produced by AA-CVD affords a lattice expansion in the (002) direction as compared to bulk material. This is quite similar to our work wich shows that the expantion also obserived in the (001) direction. 
(i)

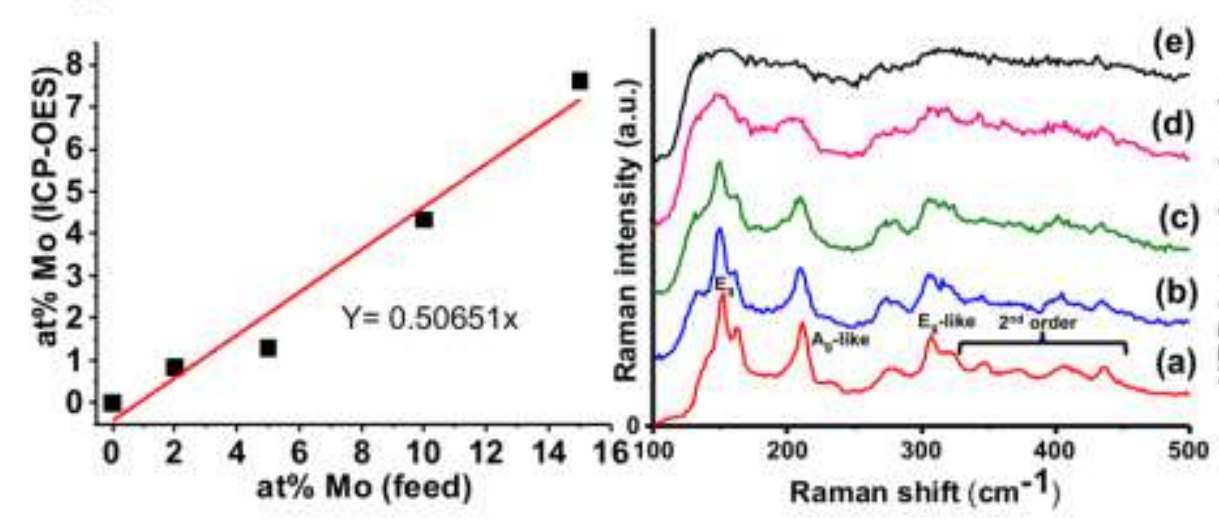

(iii)

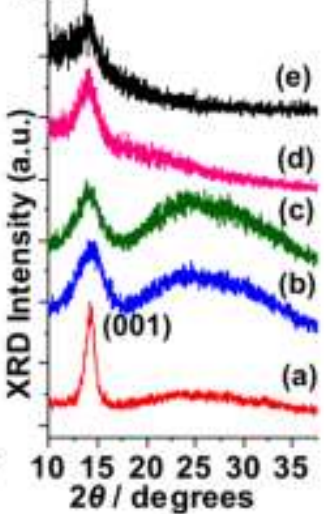

Fig. 1. The ICP-OES, Raman spectroscopy and Powder X-ray diffraction pattern for the $\mathrm{Re}_{1-}$ ${ }_{x} \mathrm{Mo}_{x} \mathrm{~S}_{2}(0 \leq \mathrm{x} \leq 1)$ alloy were deposited by AACVD at $550{ }^{\circ} \mathrm{C}$. (i) The ICP-OES of at $\%$ tungsten in precursor feed and found in the alloyed films. (ii) Raman spectroscopy of the $\mathrm{Re}_{1 \text { - }}$ ${ }_{x} \mathrm{Mo}_{\mathrm{x}} \mathrm{S}_{2}(0 \leq \mathrm{x} \leq 1)$ thin films deposited by AACVD using (1) and (2); (a) $0 \% \mathrm{Mo}$, (b) $0.84 \%$ Mo, (c) $1.29 \%$ Mo, (d) $4.33 \%$ Mo, (e) $7.61 \%$ Mo. (iii) Powder X-ray diffraction patterns of the alloy; (a) 0\% Mo $\left(\operatorname{ReS}_{2}\right)$ shows one peak which is preferred orientation in the (010) plane of $1 \mathrm{~T}-\mathrm{ReS}_{2}$ and consistent with our previous studies that reported before [11,24], (b) $0.84 \%$ Mo, (c) $1.29 \% \mathrm{Mo}$, (d) $4.33 \% \mathrm{Mo}$, and (e) $7.61 \% \mathrm{Mo}$.

The dependence of the Raman spectroscopy shifts in the $\mathrm{E}_{\mathrm{g}}$ and $\mathrm{Ag}_{\mathrm{g}}$-like optical modes of $\mathrm{Re}_{1}$ ${ }_{x} \mathrm{Mo}_{\mathrm{x}} \mathrm{S}_{2}$ are shown in Fig. 2. It can be seen in Fig. 2 that by increasing the concentration of molybdenum, both the $\mathrm{E}_{\mathrm{g}}$ and $\mathrm{A}_{\mathrm{g}}$-like modes were affected significantly in the same way. These two vibrational modes have decreased by ca. $\sim 6 \mathrm{~cm}^{-1}$. On the one hand, the $\mathrm{E}_{\mathrm{g}}$ vibrational mode shifted from ca. $152.5 \mathrm{~cm}^{-1}$ at $0 \%$ Mo to ca. $146 \mathrm{~cm}^{-1} \mathrm{E}_{\mathrm{g}}$ when increase the Mo portion to $4.33 \%$, mainly due to the in-plane stretching vibrations of Re-Re bonds along the edge of the Re4 unit and in-plane vibrations of a pair of $\mathrm{S}$ atoms. On the other hand, the $\mathrm{A}_{\mathrm{g}}$-like mode shifted from ca. $212 \mathrm{~cm}^{-1}$ in case of pure $\mathrm{ReS}_{2}$ to ca. $205.7 \mathrm{~cm}^{-1}$ when the incorporation reaches $4.33 \%$. The $\mathrm{A}_{\mathrm{g}}$-like modes include in-plane stretching vibrations of Re-Re bonds and the vibrations of a pair of S atoms that span only one metal-metal bond. This is consistent with the substitutional doping that happened to the Mo atoms in the $\operatorname{ReS}_{2}$ matrix and the metal-metal exchange actually occurred. Increasing the doping level of Mo to more that $7 \%$ makes the lattice suffered

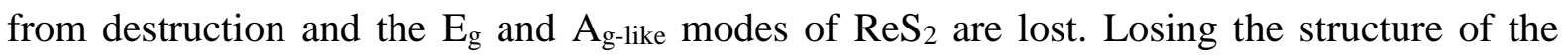
Raman spectrum was observed in our previous studies [24, 34], by increasing the dopant portions. The reason behind this could due to the different in crystal structure between $\operatorname{ReS}_{2}$ and $\mathrm{MoS}_{2}$ which have octahedral and hexagonal crystal structure, respectively[34]. Rhenium 
disulfide suffer from a rippling effect of sheets in the ac plane, and this is because $\mathrm{ReS}_{2}$ exists as distorted parallelograms within the layers [38].

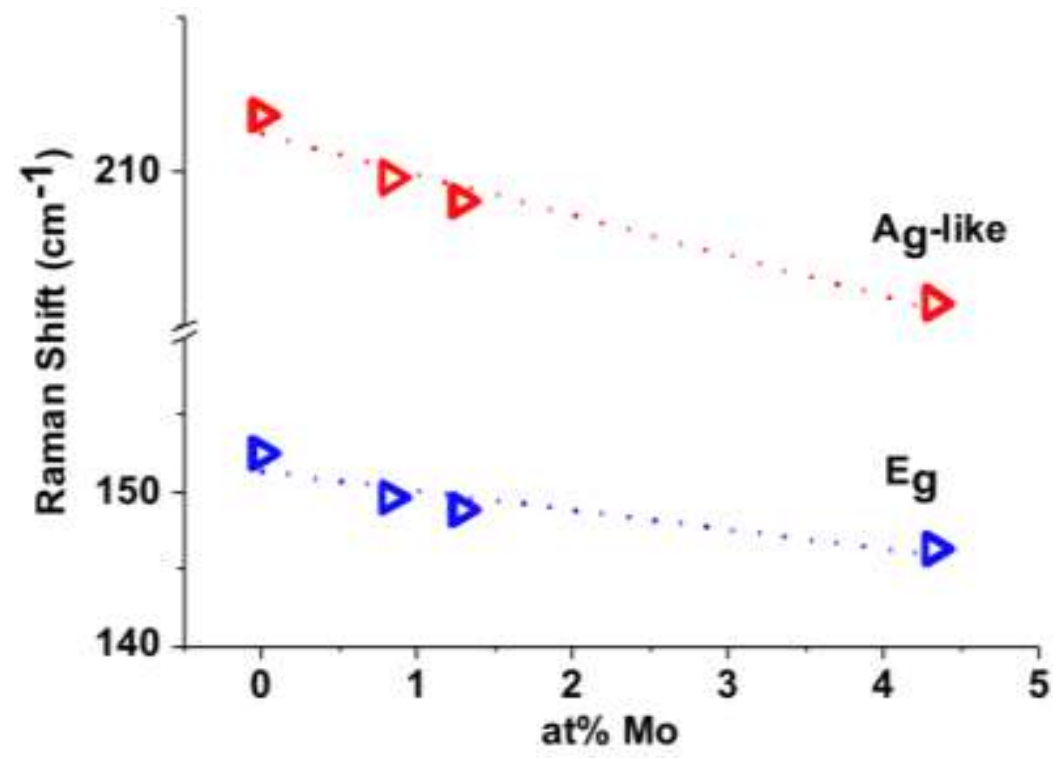

Fig. 1. Shifts of the $E_{g}$ and $A_{g}$-like bands of the $\operatorname{Re}_{1-x} M o_{x} S_{2}(0 \leq x \leq 1)$ thin films as a function of the mole fraction (x) of Molybdenum were found by ICP-OES spectroscopy. A break from 160 to $205 \mathrm{~cm}^{-1}$ in the Y-axis is to make the peak shift more obvious.

The surface morphology of the alloyed films deposited by the AACVD at $550{ }^{\circ} \mathrm{C}$ was investigated by scanning electron microscope (SEM). The SEM investigations provide a different morphology by increasing the Mo concentration. $\mathrm{ReS}_{2}$ had a leaf-like lamellar structure, but $0.84 \%$ of the Mo shows flaky lamellar clusters. Increasing the incorporation to $1.29 \%$ showed lamellae morphology, $4.33 \%$ had a cluster structure, and finally, by increasing the incorporation to $7.61 \%$, leaf-like lamellae were observed, as shown in Fig. 3. These different morphologies that observed by increasing dopant ratios were compatable with previous studies $[24,34]$. Those studies revealed that, when dopant (Re) increased in $\mathrm{MoS}_{2}$, different morphologies were observed e.g lamellar morphology in case of pure $\mathrm{MoS}_{2}$ to clusters, feather-like crystals and smaller crystallites mirroring by increasing the rhenium content in $\mathrm{MoS}_{2}$. 


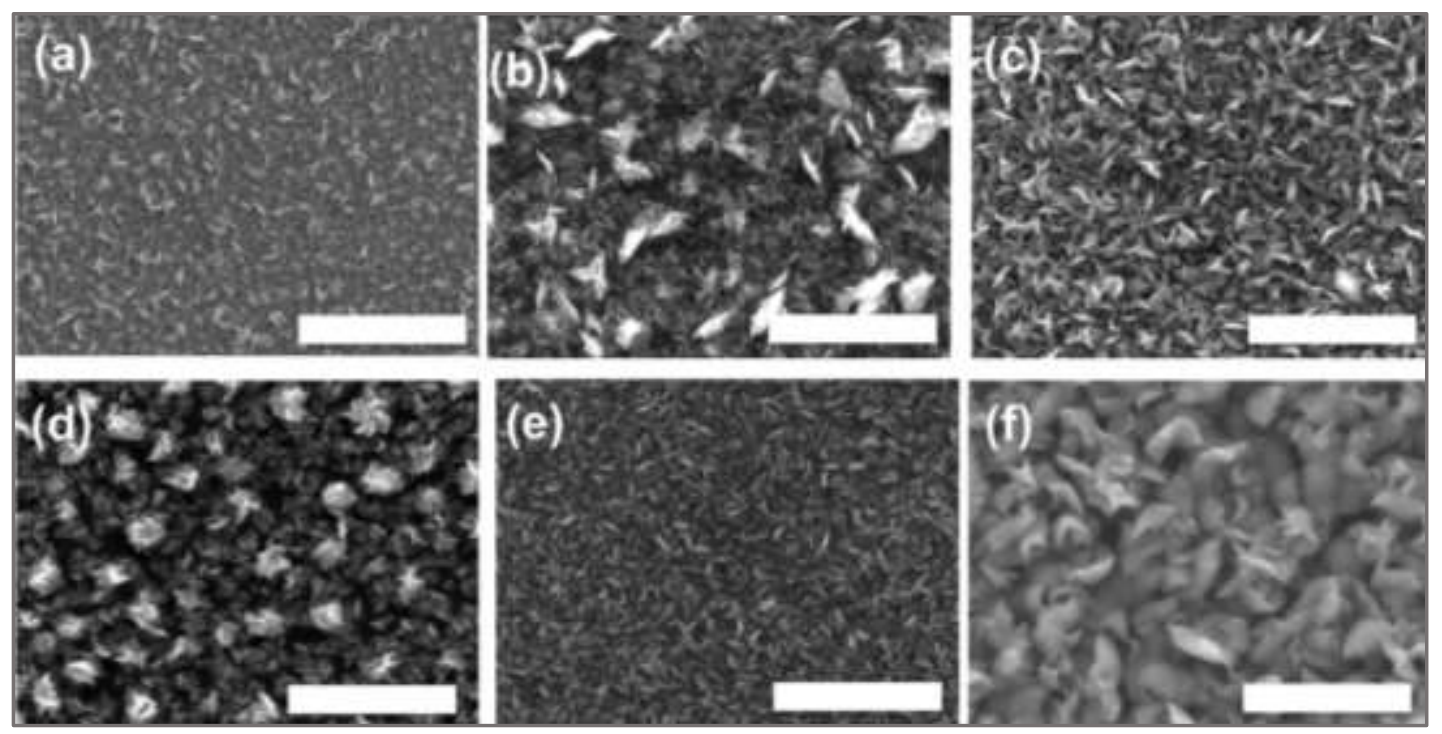

Fig. 2. Secondary electron SEM images $(10 \mathrm{kV})$ of the Mo-doped $\operatorname{ReS}_{2}$ thin films deposited on a glass substrate by AACVD using (1) and (2) at $550{ }^{\circ} \mathrm{C}$; (a) $\operatorname{ReS}_{2}, 11$, (b) $0.84 \% \mathrm{Mo}$, (c) $1.29 \% \mathrm{Mo}$, (d) $4.33 \% \mathrm{Mo}$, (e) 7.61\% Mo and (f) $\mathrm{MoS}_{2}$. All scale bars represent $1 \mu \mathrm{m}$.

High resolution transmission electron microscope (HRTEM), revealed apparently homogeneous doping, and surprisingly, the EDX was able to detect the Mo in the $\operatorname{ReS}_{2}$ lattice (for supporting information, see Fig. S3). It was found that the crystals had a $\mathrm{ReS}_{2}$ type structure. Two samples with different levels of Mo doping (7.6\% and $0.84 \%$ ) were imaged at atomic resolution (Fig. 4 and Fig. S4). The atomic resolution (S) TEM images demonstrate a crystal structure with lattice spacing similar to those of pure $\operatorname{ReS}_{2}$. The flakes appeared to be single crystalline and index to $\mathrm{ReS}_{2}$ viewed down the (010) zone axis. Interestingly, high levels of Mo doping appear to result in an expansion of the $\mathrm{ReS}_{2}$ lattice. It was also observed that inplane lattice spacing was larger for the $7.6 \%$ doped sample compared to the $0.84 \%$ doped sample. While the $0.84 \%$ sample is consistent with the $d$-spacing expected for pure $\operatorname{ReS}_{2}$, showing a (001) spacing of $\sim 5.5 \AA$, the same spacing in the $7.6 \%$ sample was measured at $\sim 5.8$ $\AA$, corresponding to an in-plane expansion of over $1.29 \%$. An expansion of interlayer spacing was also observed in our p-XRD data (for supporting information, see Fig. S4), suggesting that the introduction of high levels of Mo results in an expansion of the $\mathrm{ReS}_{2}$ unit cell in all dimensions. This evidence strongly supports the theory that these samples are homogeneously alloyed and that there is no phase segregation of $\mathrm{MoS}_{2}$ and $\mathrm{ReS}_{2}$ [24]. 


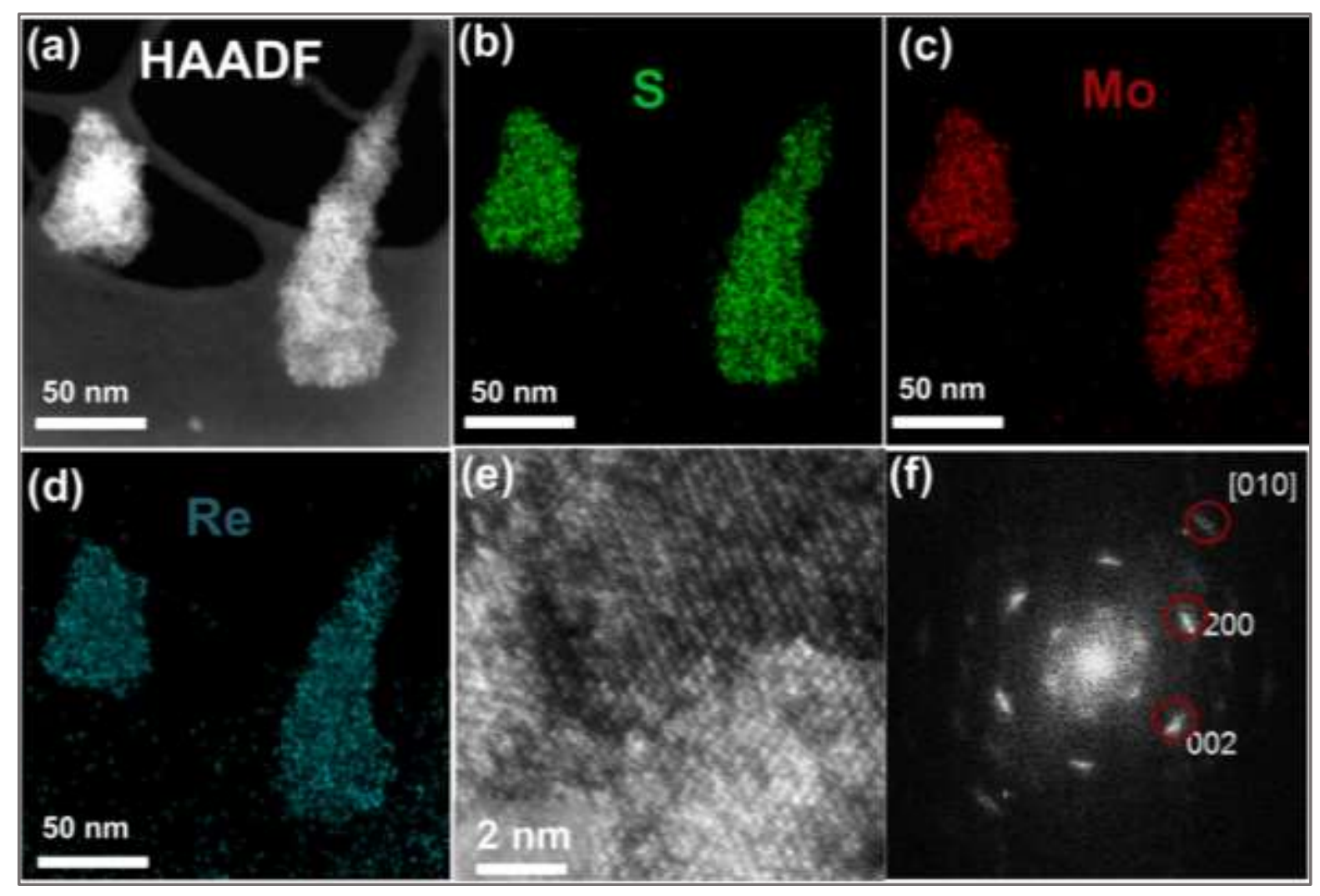

Fig. 3. (a) shows a high-angle annular dark-field scanning transmission electron microscopy (HAADF STEM) image of two nanosheets of alloy 7.61\% Mo; (b-d) are elemental maps for $\mathrm{S}$, Mo and Re, respectively; (e) atomic resolution HAADF STEM image of a representative region of nanosheet; and (f) corresponding Fourier transform showing a crystal structure closely resembling that expected for $\operatorname{ReS}_{2}$. 


\section{Conclusion}

In summary, AACVD was used to produce $\mathrm{Re}_{1-\mathrm{x}} \mathrm{Mo}_{\mathrm{x}} \mathrm{S}_{2}$ alloyed films at $550{ }^{\circ} \mathrm{C}$. Polycrystalline thin films of Mo-doped $\mathrm{ReS}_{2}$ were synthesised using precursors (1) $\left[\mathrm{Re}\left(\mathrm{S}_{2} \mathrm{CC}_{6} \mathrm{H}_{5}\right)\left(\mathrm{S}_{3} \mathrm{CC}_{6} \mathrm{H}_{5}\right)_{2}\right]$ and (2) $\left[\mathrm{Mo}\left(\mathrm{S}_{2} \mathrm{CNEt}_{2}\right)_{4}\right]$ by adding a low concentration of $(2)$ at $550{ }^{\circ} \mathrm{C}$. The characterised films of (1) and (2) correspond to $\mathrm{MoS}_{2}$ and $\mathrm{ReS}_{2}$. The molybdenum level in the $\mathrm{ReS}_{2}$ matrix was detected by ICP-OES to get up to $7 \%$ Mo when feed was at $15 \% \mathrm{Mo}$, and EDX elemental mapping successfully detected Mo in the lattice. Furthermore, dramatic changes have been observed in both p-XRD and Raman spectroscopy. The SEM of the doped films shows nano crystal morphology, and this morphology was changed by increasing the molybdenum concentration in the $\operatorname{ReS}_{2}$ crystal structure.

\section{Author statement}

Naktal Al-Dulaimi: Planned and carried out the experiments, analyzed and interpreted the results and wrote the article. Mundher Al-Shakban: Involved in characterization some results like Raman and XRD. Edward A. Lewis and Sarah J. Haigh: Involved in characterization and interpreted the HRTEM results. Paul D. McNaughter: Involved in characterization TEM results (supporting information). Firoz Alam: Editing and revising the manuscript. David J. Lewis: Participated in discussion the data and involved in editing revising the manuscript.

\section{Declaration of competing interest}

The authors declare that they have no known competing financial interests or personal relationships that could have appeared to influence the work reported in this paper.

\section{Acknowledgements}

I would like to thank my supervisor, Prof. Paul O'Brien (POB), who passed away on $18 / 10 / 2018$, for his guidance and motivation and advice that he has provided throughout my $\mathrm{PhD}$ study. I have been extremely lucky to be a member in his group and to have a supervisor who cared about the level and quality of his students. I cannot forget the valuable discussion and the chatting that we had and motivation and support that I got from him. Rest in peace POB. 


\section{References}

[1] Y Shi, H Li, L-J Li (2015) Chem. Soc. Rev. 44: 2744. Doi:10.1039/C4CS00256C

[2] QH Wang, K Kalantar-Zadeh, A Kis, JN Coleman, MS Strano (2012) Nat. Nanotechnol. 7: 699. Doi:10.1038/nnano.2012.193

[3] S Das, D Pandey, J Thomas, T Roy (2019) Advanced Materials 31: 1970006. Doi:10.1002/adma.201970006

[4] X Liu, MC Hersam (2018) Advanced Materials 30: 1801586. Doi:10.1002/adma.201801586

[5] L Majidi, P Yasaei, RE Warburton, et al. (2019) Advanced Materials 31: 1804453. Doi:10.1002/adma.201804453

[6] H Cui, Y Guo, W Ma, Z Zhou (2020) ChemSusChem 13: 1155 Doi:10.1002/cssc.201903095

[7] L Loh, Z Zhang, M Bosman, G Eda (2020) Nano Research: 1. Doi:10.1007/s12274-020-3013-4

[8] S Tongay, H Sahin, C Ko, et al. (2014) Nat. Commun. 5: 1. Doi:10.1038/ncomms4252

[9] S Horzum, D Çakır, J Suh, et al. (2014) Phys. Rev. B, PRB 89: 155433. Doi:10.1103/PhysRevB.89.155433

[10] A Kuc, N Zibouche, T Heine (2011) Phys. Rev. B, PRB 83: 245213. Doi:10.1103/PhysRevB.83.245213

[11] KF Mak, C Lee, J Hone, J Shan, TF Heinz (2010) Phys. Rev. Lett. $105: 136805$. Doi:10.1103/PhysRevLett.105.136805

[12] AA Tedstone, DJ Lewis, P O’Brien (2016) Chem. Mater. 28: 1965. Doi:10.1021/acs.chemmater.6b00430

[13] M Drábek, M Rieder, V Böhmová (2010) Eur. J. Mineral. 22: 479. Doi:10.1127/0935-1221/2010/0022-2044

[14] R Shannon (1976) Acta Cryst. A. 32: 751. Doi:doi:10.1107/S0567739476001551

[15] P Marchand, IA Hassan, IP Parkin, CJ Carmalt (2013) Dalton Trans. 42: 9406. Doi:10.1039/C3DT50607J

[16] N Al-Dulaimi, EA Lewis, DJ Lewis, SK Howell, SJ Haigh, P O'Brien (2016) Chem. Commun. 52: 7878. Doi:10.1039/C6CC03316D

[17] S Khalid, E Ahmed, MA Malik, et al. (2015) New J. Chem. 39: 1013. Doi:10.1039/C4NJ01461H

[18] S Mlowe, DJ Lewis, MA Malik, et al. (2016) Dalton Trans. 45: 2647. Doi:10.1039/C5DT03881B

[19] AA Tedstone, EA Lewis, N Savjani, et al. (2017) Chem. Mater. 29(9): 3858. Doi:10.1021/acs.chemmater.6b05271

[20] S Mlowe, DJ Lewis, MA Malik, et al. (2014) New J. Chem. 38: 6073. Doi: 10.1039/C4NJ01201A

[21] P Kevin, DJ Lewis, J Raftery, MA Malik, P O’Brien (2015) J. Cryst. Growth 415: 93. Doi:10.1016/j.jcrysgro.2014.07.019

[22] M Al-Shakban, PD Matthews, EA Lewis, et al. (2019) Journal of Materials Science 54: 2315. Doi:10.1007/s10853018-2968-y

[23] DJ Lewis, P O'Brien (2014) Chemical Communications 50: 6319. Doi:10.1039/C4CC02592J

[24] N Al-Dulaimi, DJ Lewis, XL Zhong, MA Malik, P O'Brien (2016) J. Mater. Chem. C 4: 2312. Doi:10.1039/C6TC00489J

[25] AA Tedstone, DJ Lewis, R Hao, et al. (2015) ACS Appl. Mater. Interfaces 7: 20829. Doi:10.1021/acsami.5b06055

[26] DJ Lewis, AA Tedstone, XL Zhong, et al. (2015) Chem. Mater. 27: 1367. Doi:10.1021/cm504532w

[27] J Lv, J Yang, S Jiao, et al. (2020) ACS Applied Materials \& Interfaces 12: 43311. Doi:10.1021/acsami.0c12729

[28] J-K Qin, W-Z Shao, C-Y Xu, et al. (2017) ACS Applied Materials \& Interfaces 9: 15583. Doi:10.1021/acsami.7b02101

[29] J Xu, C Fang, Z Zhu, J Wang, B Yu, J Zhang (2020) Nanoscale 12: 17045. Doi:10.1039/D0NR03693E

[30] Q Deng, X Li, H Si, et al. (2020) Advanced Functional Materials 30: 2003264. Doi:10.1002/adfm.202003264

[31] CA McConnachie, EI Stiefel (1997) Inorg. Chem. 36: 6144. Doi:10.1021/ic970689h

[32] M Decoster, F Conan, J Guerchais, et al. (1995) Polyhedron 14: 1741. Doi:10.1016/0277-5387(94)00487-Y

[33] D Çakır, H Sahin, FM Peeters (2014) Physical Chemistry Chemical Physics 16: 16771. Doi:10.1039/C4CP02007C

[34] N Al-Dulaimi, EA Lewis, N Savjani, et al. (2017) J. Mater. Chem. C 5: 9044. Doi:10.1039/C7TC01903C

[35] M Decoster, F Conan, JE Guerchais, et al. (1995) Polyhedron 14: 1741. Doi:http://dx.doi.org/10.1016/02775387(94)00487-Y

[36] MN McCain, B He, J Sanati, QJ Wang, TJ Marks (2008) Chem. Mater. 20: 5438. Doi:10.1021/cm7026674

[37] P Yen, M Chen, Y Huang, C Ho, K Tiong (2002) J. Phys. Condens. Matter 14: 4737. Doi:10.1088/0953$8984 / 14 / 18 / 308$

[38] HH Murray, SP Kelty, RR Chianelli, CS Day (1994) Inorganic Chemistry 33: 4418. Doi:10.1021/ic00097a037 